Andrej Novak - Alena Novak Sedlackova - Anna Stelmach - Doris Novak

\title{
SAFETY IMPLICATIONS OF GNSS SIGNAL INTERFERENCE AT ZILINA AIRPORT
}

The paper deals with the issue of GNSS interference and its subsequent impact on airport approach procedures. It discusses the problem of GNSS signal interference and interference identification on a practical example of a small regional airport in Zilina, located close to the highway, through research aimed at its identification, a proposal for the location of a monitoring station and subsequent practical verification. The paper seeks to analyse and provide recommendations for enhancing safety and reliability in GNSS approaches. Given the need to develop the air transport, it is important to ensure the safety and continuity of service provision at small regional airports. The GNSS approach at airports with insufficiently equipped navigation infrastructure seems to be one of the most suitable. Introduction of the GNSS interference monitoring in the final instrument approach phase would increase the safety and reliability of the flight.

Keywords: aircraft, GNSS, signal interference, safety

\section{Introduction}

Satellite navigation systems have existed since the early 1960 s when development of the first navigation satellites began. This resulted in the development of the Transit system in the US and development of the Cyclone navigation system and its civilian version of Cikada in the Soviet Union. Initially, those systems provided positioning in 2D space. The positional error of the first satellite navigation systems was approximately $500 \mathrm{~m}$ during the signal reception and had a relatively low time determination accuracy. Those navigation systems worked on the Doppler principle. In the US, after experience with the Doppler systems in the early 1970s, they decided to build a 3D navigation system with a precise time standard. This project has launched a new era of satellite navigation systems that are also suitable for use in civil aviation. The new navigation systems in the 1980s were the GPS NAVSTAR developed in the USA and the GLONASS system developed in the Soviet Union. Those two global satellite navigation systems set the foundation for the development and production of new satellite navigation systems Galileo (in the EU), BeiDou (in China) and Gagan (in India).

Development of the satellite systems and their implementation in aviation in the 1990s were also helped by the massive development of computer technology, the enhancement and implementation of new procedures in airspace management, but also problems with the navigation performance of existing terrestrial navigation systems. One of the first significant milestones in use of the satellite navigation systems was to switch off the deliberate misleading of the GPS L1 signal on May 1, 2000. The second significant milestone in development and use of the satellite navigation systems was introduction of enhanced satellite navigation systems, either based on a terrestrial augmentation called GBAS (Ground Based Augmentation System) or based on a satellite augmentation called SBAS (Satellite Based Augmentation System). Both variants of the satellite navigation system augmentation offer various aviation users a variety of options and benefits. Highlights include increased 3D positioning accuracy, continuity, integrity and safety.

The third milestone in development is integration of the new satellite navigation systems, Galileo and BeiDou, into air navigation and their application to aviation. This step will make it possible to switch from one L1C/A GPS signal to eight signals from four satellite navigation systems [1]. The US GPS system on L1C/A has so far provided the required Performance Based Navigation (PBN) in air navigation, aircraft positioning for Automatic Dependent Surveillance (ADS-B) and navigation support for safety systems (TAWS - Terrain Avoidance Warning Systems). In the future it is expected that in air or other types of navigation Dual Frequency Multi Constellation Services (DFMC) - combining two frequencies from different satellite navigation systems of American GPS, Russian GLONASS, European Galileo and Chinese BeiDou will be used to help civil aviation to improve navigation performance, continuity and integrity of the precision air navigation system. Therefore, DFMC GNSS in aviation means using a dual frequency signal from up to four GNSS sources. This will enable improvement of the Airborne Based Augmentation Systems (ABAS),

\footnotetext{
Andrej Novak ${ }^{1, *}$, Alena Novak Sedlackova ${ }^{1}$, Anna Stelmach ${ }^{2}$, Doris Novak ${ }^{3}$

${ }^{1}$ University of Zilina, Slovakia

${ }^{2}$ Warsaw University of Technology, Poland

${ }^{3}$ University of Zagreb, Croatia

*E-mail of corresponding author: andrej.novak@fpedas.uniza.sk
} 

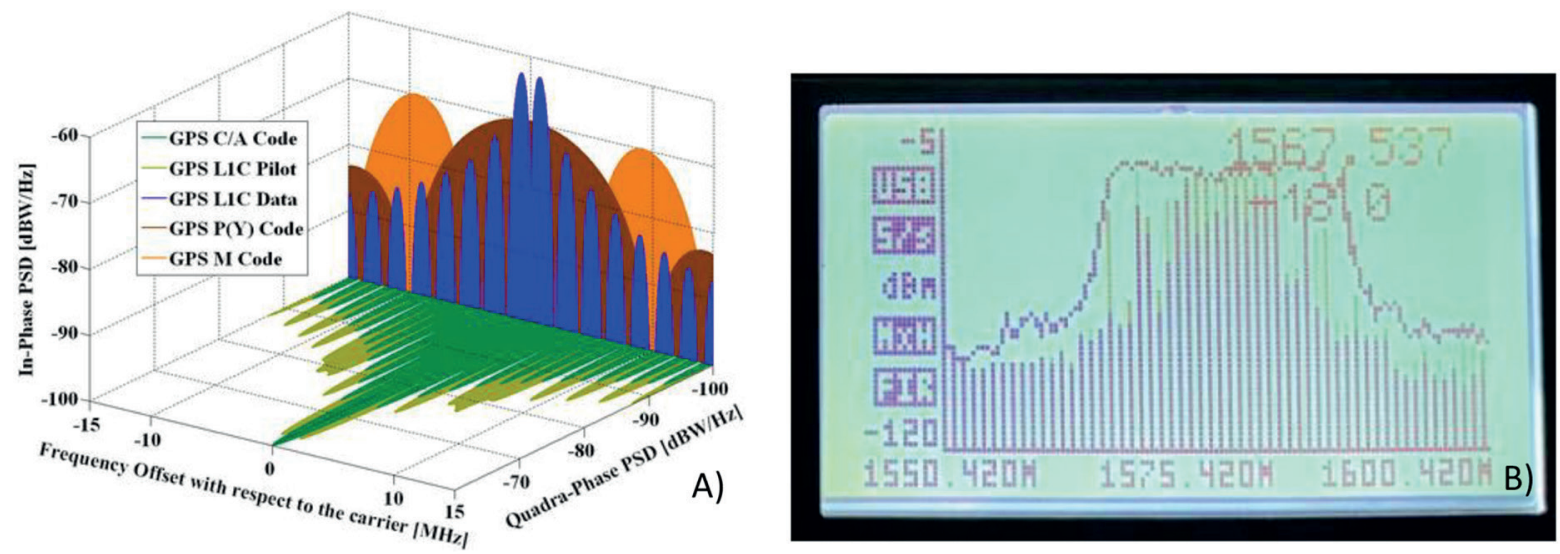

Figure 1 Spectrum GPS L1 (C/A, L1C, P(Y) code, M-code) and spectrum of jammer with power-18dBm

the Satellite Based Augmentation System (SBAS) and the Ground Based Augmentation System (GBAS). Introduction of the DFMC for use in civil aviation is expected in years 2025 to 2028. The idea of introducing the DFMC is not new and its use has been common in geodesy and cartography for more than 10 years, with the first devices with this functionality being marketed by Leica and Trimble.

The problem of the GNSS systems dependence on only one data source, the GPS L1C/A, is very restrictive in terms of safety and regularity of air transport. From the economic efficiency point of view, such a monopoly in the provision of navigation information at first glance may seem advantageous, but it has limits in terms of the need to maintain the large-scale ground and airborne infrastructure based on the conventional VOR/DME or DME/DME navigation. This GNSS monopoly built on GPS L1C/A has only a little resistance to accidental and deliberate frequency interference. In Europe, but also elsewhere in the world, there were accidental local interference of satellite navigation systems, which were losing their navigation performance, continuity of service and, last but not the least, location and time accuracy.

\section{GNSS signal interference identification}

Issue of the GNSS signal interference identification has been elaborated by several authors of publications. This issue can be divided into two partial problems. The first is the interference of the GNSS signal, which is undesirable, not only in the field of the air transport in real-time positioning, but in the intelligent transport systems, as well. The second partial problem is identification and location of GNSS signal interference. The non-public GNSS signals that are provided for military and special applications are usually encrypted. Their immunity to the interference signal is relatively greater due to use of the two or more carrier frequencies for the transmission of navigation data. However, in publicly available services, referred to as "open service" (OS), the signal is transmitted on one frequency, so the resilience of this system decreases significantly. Given that the satellite signal has a very low signal strength on the earth's surface, typically -120 to $-130 \mathrm{dBW}$ (the receiver is capable of processing up to $-158.5 \mathrm{dBW}$ ) (Figure 1), the easiest attack on the GNSS signal is to generate interference or jamming. In the case of using meaconing or spoofing, this type of attack is much more demanding and therefore this type of interference requires relatively good technical equipment, provision of which is relatively expensive. Meaconing, sending a false signal with the aim of taking the target to another area, requires sophisticated know-how, as well as tens of thousands of euros of technical equipment (antenna system, GNSS signal generator, radar or LIDAR or camera system for detecting the location of interfered target).

The GNSS signal interference can be divided into two categories. The first category consists of interference that is not intentional and arises from various electrical devices operating at harmonic frequencies close to the GNSS systems. Be it various radio relay links, TV transmitters, radars, but also damaged base stations of mobile operators (BTS). The second group consists of interference or jamming caused by deliberate interference in the frequency spectrum of the GNSS signals. These are either intentionally coordinated attacks, or people using personal radio jammers, also known as PPD (Personal Privacy Device). A typical jamming case is the GNSS signal jamming at Newark Airport in New Jersey in 2009, where the GBAS was newly installed. [2-3]. This system showed short-term system integrity failures due to the GNSS signal interruptions. After two months of investigation by the FAA (United States' Federal Aviation Administration), it has been found that the interference was caused by a passing vehicle with a driver using a freely available PPD. There was no damage to property and lives during the incident, but this case showed how easily it is possible to disrupt such a sophisticated GBAS as long as it is based on receiving one GNSS (GPS L1) signal, see Figure 1 [4-5].

The interference itself can be defined based on the following characteristics:

- Depending on the type (sine wave interference, carrier wave - single tone, or interference by AM, FM, PM 


\section{Fatal Accidents and Onboard Fatalities by Phase of Flight}

Fatal Accidents | Worldwide Commercial Jet Fleet | 2007 through 2016

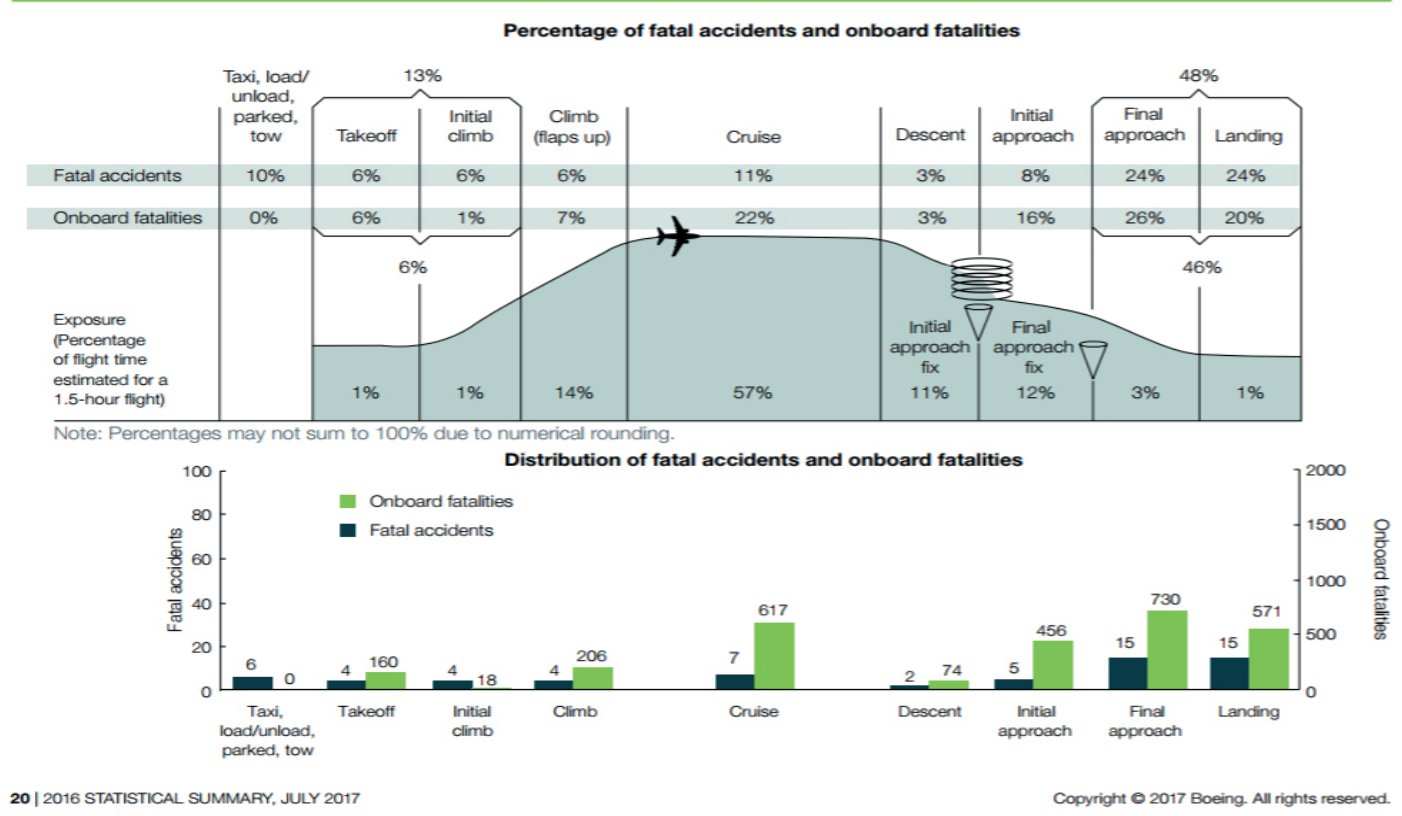

Figure 2 Analysis of different phases of flight from the perspective of incidents on board aircraft [6]

modulated signals that disturb the signal in a larger spectrum or noise interference - randomly generated signal (white or pink noise)).

- Relatively according to the mean frequency of interference to the position of our signal where the interference itself is located, one can talk about "out of band", "near the band" or "in band" interference.

- Signal interference bandwidth, where signal interferences can be divided into two subgroups of broadband or narrowband interference.

- Interference power, in which case it is the ratio of the carrier signal to the interference signal (interference) and Jammer to Signal J/S ratio.

- The time domain of interference, wherein the interference may be transmitted continuously or discreetly at time intervals or pulses. In the case of the pulse interference, it can be characterized by pulse width or number of pulses per second.

Interference on the L1 GPS frequency can manifest in the transmitted spectrum in different ways due to the fact that the signal is spread.

Given that the electromagnetic spectrum is limited, its emission must be regulated. Spectrum regulation is dealt with by the International Telecommunication Union (ITU), with the transmission of the GNSS frequencies being in the RNSS frequency bands of 1164 to $1215 \mathrm{MHz}, 1240$ to 1330 $\mathrm{MHz}$ and 5010 to $5030 \mathrm{MHz}$.

Potential GNSS signal interference is particularly problematic in the final approach phase of an aircraft. Because in this phase of flight, the greatest navigational performance of the aircraft is required. If one wants to establish a critical phase of flight, one must use the air traffic accident statistics. One such analysis was carried out by Boeing in 2017 and further elaborated by Geoffrey 2018 [6]. In this analysis authors were mainly interested in the flight phase with the highest number of incidents and accidents. The largest percentage is in the Final approach and Landing phase.

As is apparent from the analyses of Zizka (2019) and Kalasova (2015), it is precisely the areas for the use of precision approach that are intersected by transport infrastructure (highways or high-traffic roads) or in densely built areas (industrial zones, production plants and specialized businesses) that are the most problematic [7-8]. According to Curran (2017), accidental signal interference occurs right above zones that are industrially active or where high-intensity transport infrastructures exist [2]. A typical example is Frankfurt Airport, where the GNSS signal interference occurs mainly from cars located on the A3 motorway, which runs parallel to the runway and airport infrastructure for precision instrument approach GBAS. Based on the results of experiments using the method of analogy, it is decided to test this model for the Zilina airport and thus identify a critical approach point for it. Based on results of measurements (experiment) analysed by Novak 2018 , it is possible to say, that from the personal jammers and car jammers point of view, the critical point is where the road infrastructure (highway) intersects the glide path for the instrument approach [5]. The height was calculated by applying a numerical method based on propagation of the signal above the terrain, assuming the on-board satellite unit has a conventional directional antenna with a signal pre-amplifier to receive the SBAS signal, in this case from the EGNOS satellite.

Based on practical measurements, which were carried out at the Zilina airport, it was found that areas where the 


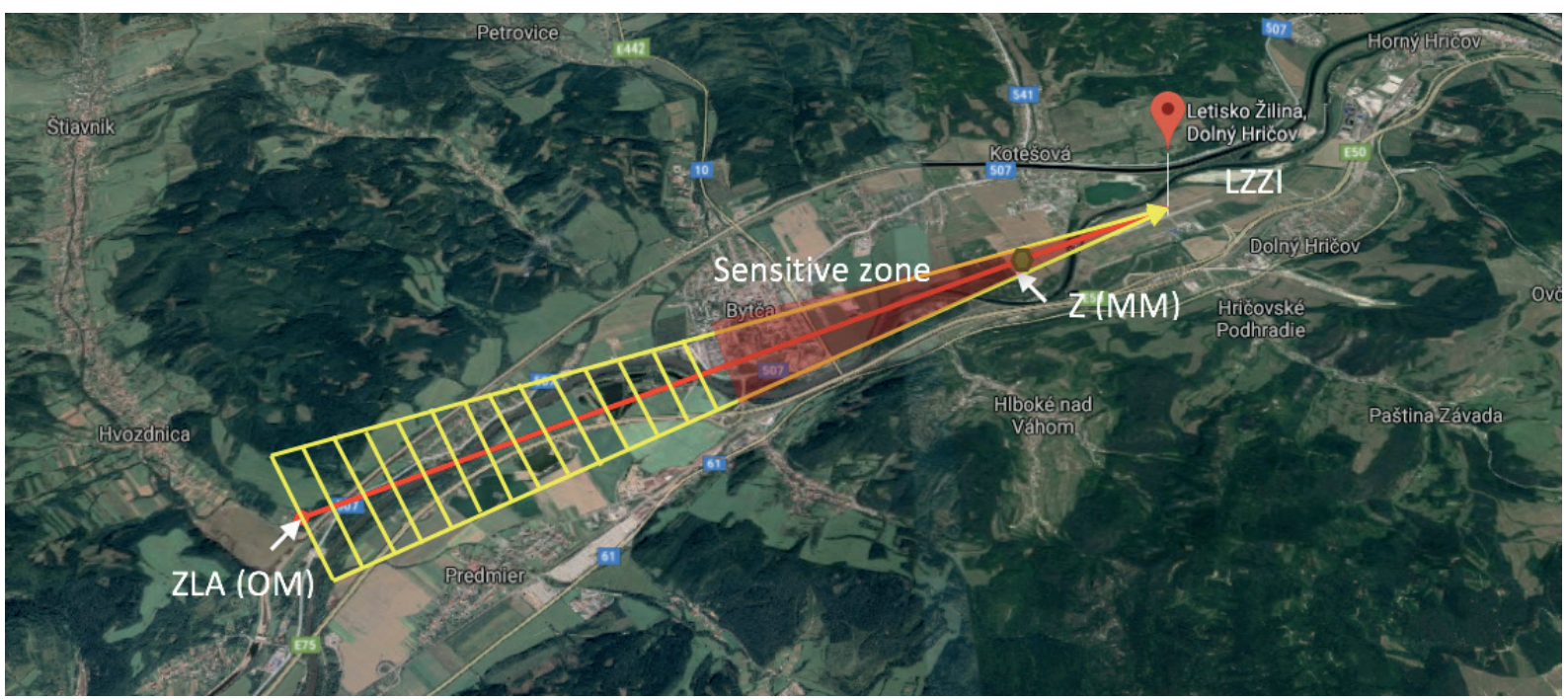

Figure 3 LZZI approach glide path for runway 06

aircraft is low above the terrain are critical [9]. Based on the above mentioned knowledge, it is possible to define a problematic place as a place or space where the aircraft drops below a critical height above the terrain (Figure 2). Figure 3 shows the critical phase of the flight in red and is defined around the $\mathrm{Z}(\mathrm{MM})$ point, as shown in Figure 3. The critical phase is from point ZLA (OM) to RWY06 LZZI, but the sensitive zone is defined around the Z (MM) \pm 1 NM. The minimum safe altitude is defined in Aeronautical Information Publication of the Slovak Republic, part Aerodromes (AD 2 LZZI-7-3) for this situation.

\section{Analysis of possible locations for detector placement}

Based on statistical outputs of measurements, carried out by the Police of the Slovak Republic in cooperation with the Regulatory Authority for Electronic Communications and Postal Services from 2012 to 2017, it was found that occurrence of the GNSS interference on GPS L1 frequency is mainly on highway sections, expressways and $1^{\text {st }}$ class roads, which are subject to a toll system that uses the GPS L1 [10]. Therefore, it is very important to analyse these types of roads and their parallelism with the approach axis for the LZZI 06 runway. The analysis of possible locations was based on terrain orography, electromagnetic wave propagation model, sensitive zone and glide axis profile for the 06 LZZI instrument runway.

For this analysis, the Zilina airport was chosen, since it by its nature represents a typical case of a regional airport located in rugged mountain terrain. Irregular air transport, charter flights as well as flight school training flights, are carried out at the airport and an introduction of an airline scheduled service is planned. At the same time, research flights of the University of Zilina in Zilina, focusing on safety, meteorological phenomena and earth exploration are carried out at the airport. During those flights, the GNSS signal interference has been registered several times through the flight laboratory, which has also been documented and described quote. This fact led to the need to build the ground-based interference detectors. When selecting a suitable location, it is necessary to analyse the potential sources of interference and their impact on the glide path of the instrument approach, as shown in Figure 4. In this case, points were identified (marked in Figure 4) on the existing transport infrastructure, as well as on the glide path, which are becoming critical for the safe approach execution. In terms of overall flight, this is the final approach phase defined by the ZLA (OM) point and the point of contact on the runway. This phase of the flight has to be divided into two further sub-sections, ZLA (OM) to $\mathrm{Z}(\mathrm{MM})$, which for the airport is defined as the final decision or Missed Approach Point (MAPt). The second part is from the $\mathrm{Z}(\mathrm{MM})$ point to the touchdown point on the runway. This division will allow to identify the risks that the GNSS signal interference could cause at this stage of the flight more accurately (Figure 3). Although there are several LPS SR or Eurocontrol studies that describe this risk, none of them explicitly anticipates deliberate interference and its increase in the period after the introduction of the LPV instrument approach, and even after subsequent calibration flights, the repeat studies are not considered, despite the fact that up to $48 \%$ of the total number of fatal incidents occurred during this phase of the flight [6, 11-12]. Based on the above analyses, findings and modelling of the situation, it was decided to identify a suitable location for the placement of the GNSS interference detector. The conditions that such a point should satisfy are: technical infrastructure (connection to the electricity grid and the possibility of data transmission) and section on the final approach track. This analysis therefore shows that such a point at the Zilina Airport should be in the centre of the descent plane for the 06 LZZI instrument runway. The point $\mathrm{Z}$ (MM) was chosen for this simulation, location of which is shown in Figure 3. 

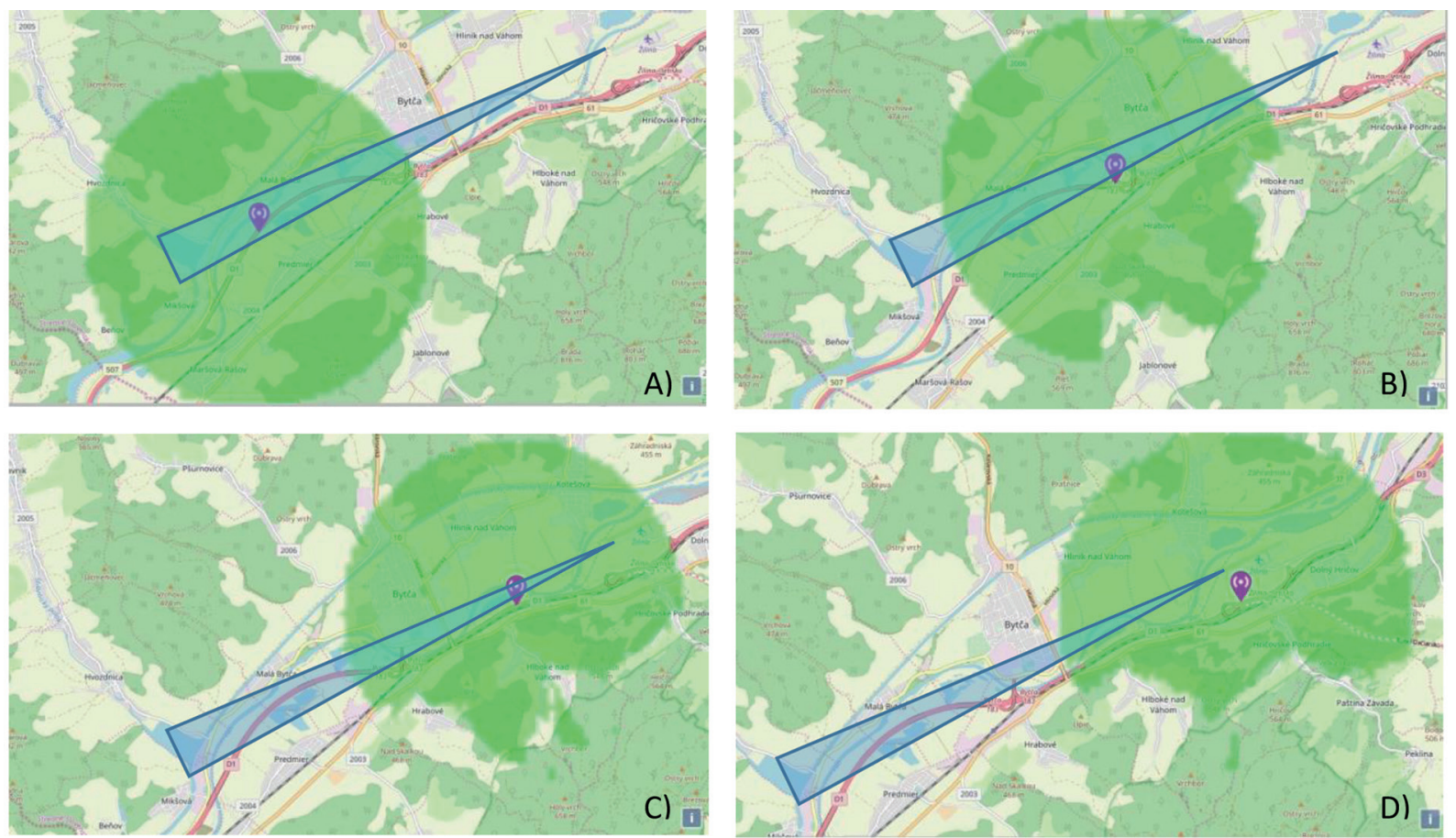

Figure 4 Point analysis of disturbance signal propagation on the GPS L1 frequency from D1 highway for 06 LZZI instrument runway
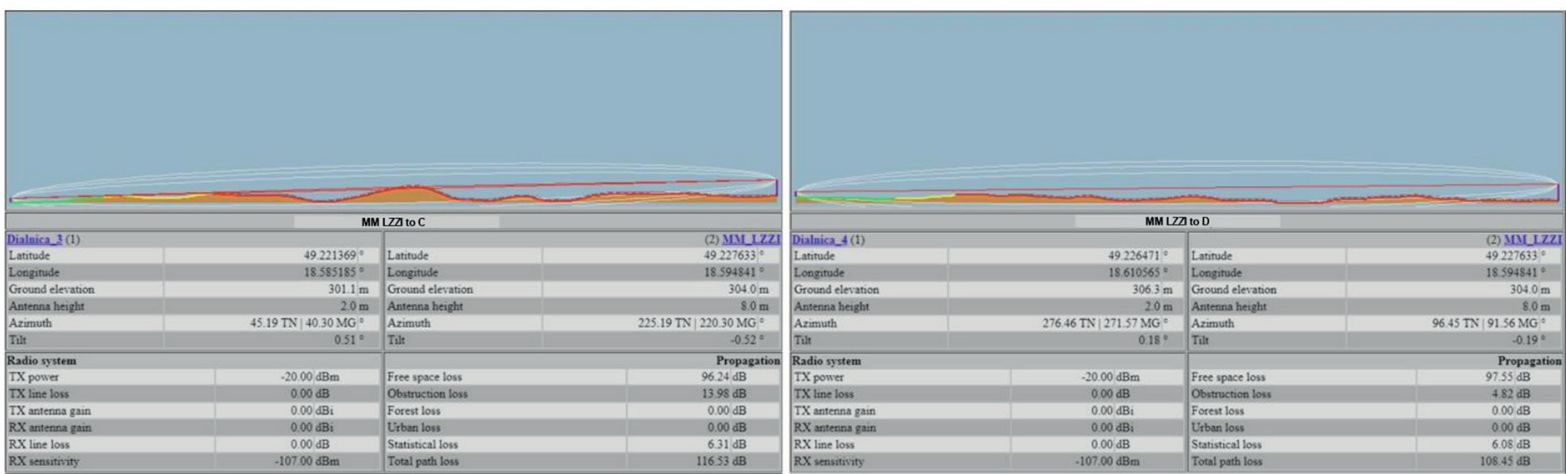

Figure 5 Signal interference simulation output for two placement variants $C$ and $D$

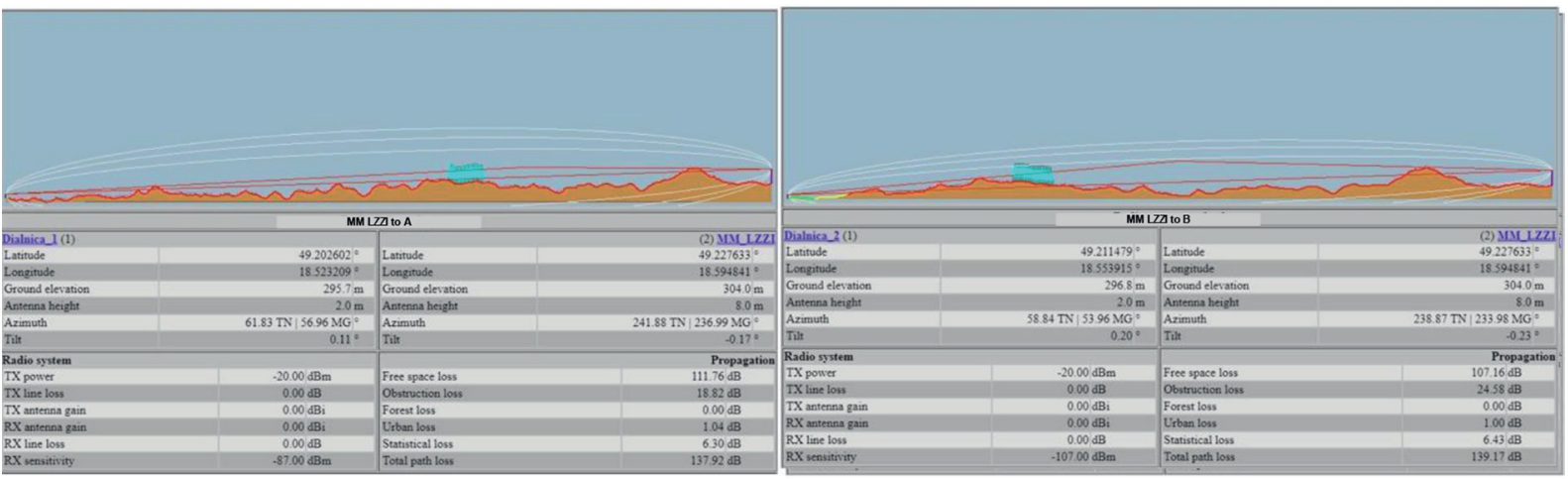

Figure 6 Signal interference simulation output for two placement variants $A$ and $B$

\section{Simulation of interference in real operation}

For the Zilina airport, the Z (MM) was chosen as the best point where the GNSS signal receiver in the simulation was placed, where the height of the antenna above the ground corresponds to the height of the existing mast $8 \mathrm{~m}$ above the ground. To simulate an interfering signal, a car moving on a highway was chosen with an antenna height that interferes the signal $2 \mathrm{~m}$ above the terrain, which represents normal delivery van or truck. 


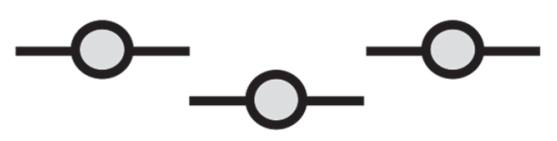

GNSS signal

(GPS, GLONASS,

Galileo, SBAS, GBAS)
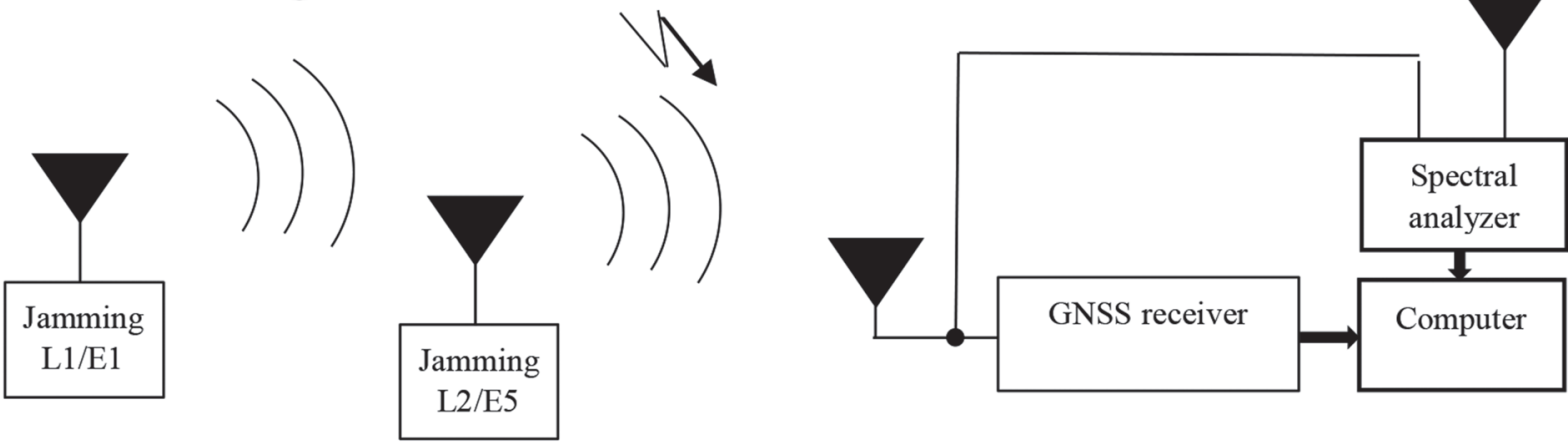

Figure 7 Ground station interference measurement, block diagram rs)

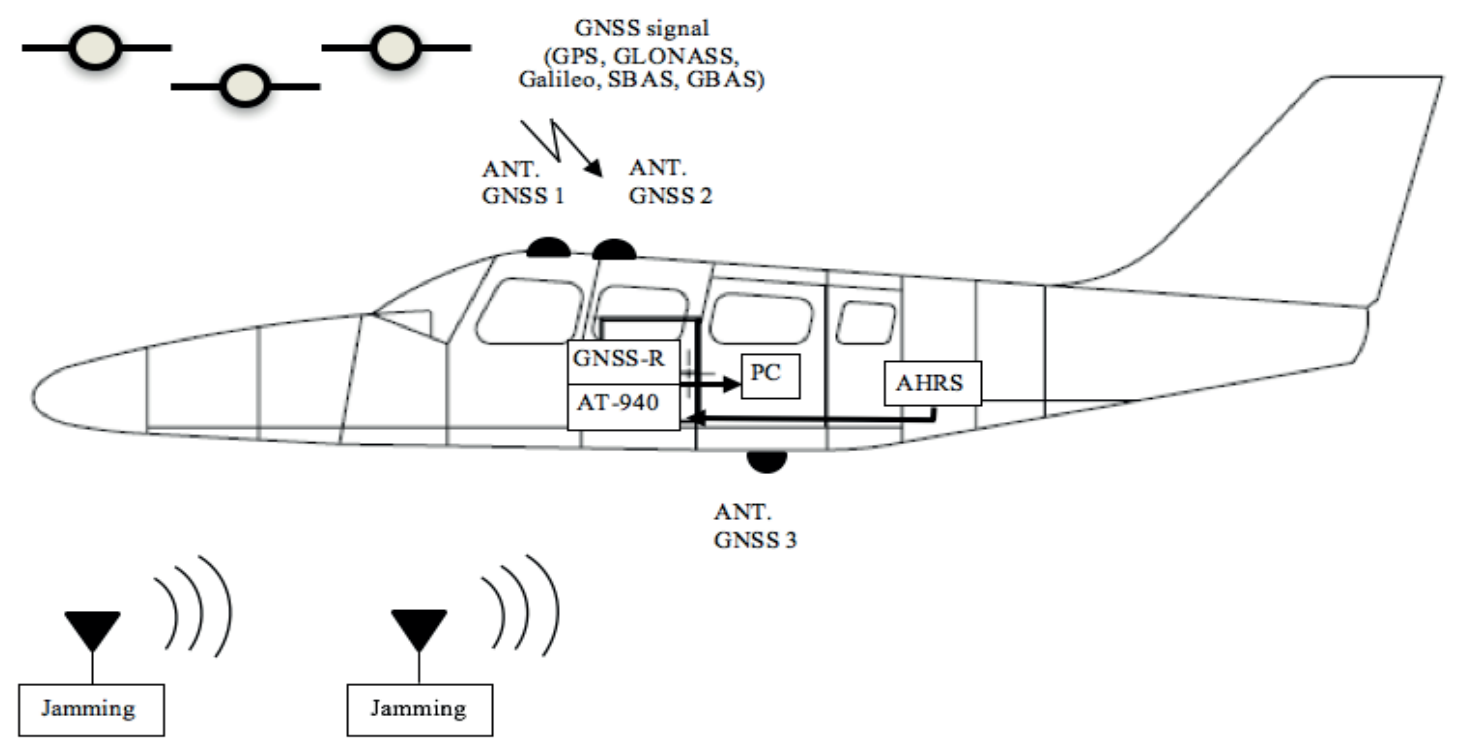

Figure 8 Measurement of interference by flight laboratory, block diagram

The jammer parameters were based on the average value of the available signal generators and measurements of commercially available jammers sold on the Internet. The power of the available jammers oscillates around $-18 \mathrm{dBm}$ $\pm 2 \mathrm{dBm}$. Antenna gain and attenuation was set to $0 \mathrm{~dB}$ to simplify the calculation, similarly the receiver sensitivity and antenna gain were set to - $107 \mathrm{dBm}$.

Subsequently, the propagation of the signal around selected points was calculated by means of the program for simulation of $\mathrm{RF}$ signal propagation and a model of point connection was created. Vertical models were created between the interference source and the interference detector (Figures 5 and 6). The calculation confirmed that the signal from the interference source could not be easily identified if the detection device was not properly positioned.

The simulation suggests that the GNSS interference detector is able to identify interference at points $\mathrm{C}$ and $\mathrm{D}$ and the detection of the interference signal will be in the critical phase of flight, which is the L (MM) up to the Touchdown point (Figure 5). From the points A and B simulation point of view it is obvious that the receiver antenna is low above the ground and therefore there is no direct connection (Figure 6). The interference may affect the first phase of ZLA (OM) approach to Z (MM), where the aircraft is relatively high above the ground, and therefore the GNSS antenna is isolated by the aircraft fuselage from a ground jammer whose antenna height is relatively low above the ground (2 m). Disturbance or failure may only occur if the aircraft falls below the minimum safe altitude above the ground. The minimum safe altitude is defined in Aeronautical Information Publication of the Slovak Republic, part Aerodromes (AD 2 LZZI-7-3) for this situation.

\section{Practical verification}

The procedure for practical verification of the simulation has been carried out by ground and subsequent aerial verification measurement. When the GNSS signal detector, which represents a GNSS receiver, a spectrum analyser, a computer and a suitable antenna system, was placed at the Z (MM) point (Figure 7). The antenna must 
be at a minimum height of $8 \mathrm{~m}$ above the ground for detection of interference from ground-based transport infrastructure and the GNSS receiver antenna has to have the same directional characteristics as the aircraft antenna. The spectrum analyzer antenna should be omnidirectional with a pre-amplifier to be able to monitor the interference signal from a distance of at least $5 \mathrm{~km}$, corresponding to the critical zone [13].

The flight measurement takes place along the glide path for the 06 LZZI instrument runway. Final approach from the ZLA $(\mathrm{OM})$ point to the threshold point on the 06 LZZI runway is particularly important for our experiment. A block diagram of flight measurement using the AeroLab 1 flight laboratory is shown in Figure 8.

The flight and ground measurement output is compared and the ground system is calibrated so that the interference sensitivity threshold is set for the failure of the GNSS signal on board the aircraft. Because the threshold for the activation of the alarm in case of the interference is one most important parameter for safety. The value of the interference threshold must be minimum $-14 \mathrm{dBm}$ less to GNSS receiver sensitivity. This is important for the future operation of the monitoring equipment in order to differentiate the impact of the GNSS interference on the final phase of the final approach flight [7, 14-15]. This practical procedure described the future measuring test for validation.

\section{Discussion}

Safety, reliability and continuity are among the main priorities of aviation. It is important to realize that the ground infrastructure for provision of the radio navigation services must meet strict conditions in these three areas. The navigation devices operate in $24 \mathrm{H}$ continuous operation, their reliability level must reach a minimum of $98 \%$ during their planned lifetime. Where terrestrial systems, such as VOR/DME, ILS are devices that operate at dedicated frequencies and are protected, satellite navigation equipment was originally designed for military use and only partially for civilian use, but not with priority for aviation. It was only later released and approved by the International Civil Aviation Organization (ICAO) for worldwide use, provided that there must be a backup in the event of a system malfunction or failure. The problem of dependence of the GNSS systems on only one data source, GPS L1C/A, is very restrictive in terms of safety, reliability and continuity of air transport. From the economic efficiency point of view, such a monopoly in the provision of navigation information at first glance may seem advantageous, but has its limits in terms of the need to maintain large-scale terrestrial and on-board infrastructures based on conventional VOR/ DME or DME/DME navigation. This GNSS monopoly built on GPS L1C/A has only little resistance to accidental and deliberate frequency interference.

Nevertheless, our simulation points out that from the economic efficiency point of view it is also possible to operate the GNSS approach systems with a high degree of safety and continuity in an environment with a high rate of interference and jamming. But only under condition of solution status monitoring and with a possibility of crew early warning for the loss of navigation performance incident. The authors of this article have shown that the current solution is not at a sufficient level of safety in terms of current knowledge of the issue and technical development of terrestrial and satellite navigation systems.

\section{Conclusion}

Introduction of the GNNS procedures for precision approach at airports in the Slovak Republic has raised several questions about the safety and reliability of the use of these procedures. Despite the established quality management systems and risk analysis, to date, not all the issues of safety, reliability and continuity of service provision at airports have been answered. Based on numerous reports on the GNSS interference and reduced navigation performance of GNSS GPS L1C/A receivers, we have decided to carry out an analysis of the location of the GNSS jamming detector for Zilina Airport (LZZI) and propose a practical verification of its location by an experiment. It should be noted that safety, reliability and continuity are the main priorities for the provision of services in air transport. Based on results of analyses, as well as the discussion itself, recommendations can be made to increase the safety and reliability of GNSS approaches.

Suggested recommendations are as follows. In the case of the aerodrome approval for approach using GNSS, it is required for the risk analysis to be only of limited validity period and to be carried out at regular intervals. The installation calibration measurement should establish an initial state and map out the possibilities and threats from the risk analysis of GNSS deployment.

\section{Acknowledgments}

This paper is published as one of the scientific outputs of the project: „New technologies and best practices in education in the Air Transport and Professional Pilots", KEGA 011ZU-4/2018. 


\section{References}

[1] Eurocontrol helps build consensus on how dual frequency multi-constellation GNSS will be used in aviation Eurocontrol [online] [Viewed 2019-10-07]. 2018. Available from: https://www.eurocontrol.int/news/moving-one-gpssignal-eight-signals-four-constellations

[2] CURRAN T. J., BAVARO, M., CLOSAS, P., NAVARRO, M. A Look at the threat of systematic jamming of GNSS. Insied GNSS [online]. 2017, September/October, p. 46-53. ISSN 1559-503X. Available from: http://insidegnss.com/auto/ sepoct17-CURRAN.pdf

[3] CATLOS, M., KURDEL, P., NOVAK SEDLACKOVA, A., LABUN, J., CESKOVIC, M. Continual monitoring of precision of aerial transport objects. In: 13th International Scientific Conference - New Trends in Aviation Development NTAD 2018 : proceedings [online]. 2018. p. 76-81. Available from: https://doi.org/10.1109/NTAD.2018.8551683

[4] NOVAK, A., BUGAJ, M, KOVACIK, L., LUSIAK, T. GNSS signal interference and its impact on safety of air transport. In: Increasing Safety and Quality in Civil and Military Aviation : proceedings. Zilina: University of Zilina, 2019. ISSN 2644495X, ISBN 978-80-554-1549-9, p. 81-84.

[5] NOVAK, A., HAVEL, K., BUGAJ, M. Measurement of GNSS signal interference by a flight laboratory. In: INAIR 2018, Aviation on the Growth Path : proceedings. Hainburg: Elsevier, 2018. ISSN 2352-1465, p. 271-278.

[6] GEOFFREY, T. Landing the most dangerous phase of flight, airlinereatings [online] [Viewed 2019-10-07]. Available from: https://www.airlineratings.com/news/passenger-news/landing-dangerous-phase-flight

[7] ZIZKA, J., NOVAK, A. Complex evaluation of risks associated with the use of new GNSS procedures In: Studies. Vol. 6. Zilina: Air Transport Department, Faculty of Operation and Economics of Transport and Communications, University of Zilina, 2019. ISBN 978-80-554-1564-2, p. 194-196.

[8] KALASOVA, A., FAITH, P., MIKULSKI, J. Telematics applications, an important basis for improving the road safety. In: Tools of Transport Telematics TST 2015 : proceedings [online]. Vol 531. Communications in Computer and Information Science. Cham: Springer, 2015. ISBN 978-3-319-24576-8, eISBN 978-3-319-24577-5. Available from: https://doi.org/10.1007/978-3-319-24577-5_29

[9] NOVAK, A., SKULTETY, F., KANDERA, B., LUSIAK, T. Measuring and testing area navigation procedures with GNSS. MATEC Web of Conferences [online]. 2018, 236, 01004. eISSN 2261-236X. Available from: https://doi.org/10.1051/ matecconf /201823601004

[10] BRIDA, P., MLYNKA, M., MACHAJ, J. How to solve GNSS problem in critical environment? In: IEEE 17th International Conference on Intelligent Engineering Systems INES 2013 : proceedings [online]. IEEE, 2013. ISSN 1543-9259, p. $27-31$. Available from: https://doi.org/10.1109/INES.2013.6632835

[11] KRAUS, J. Determining acceptable level of safety of approach to landing. In: 20th International Conference Transport Means 2016 : proceedings. 2016. ISSN 1822-296X, eISSN 2351-7034, p. 230-235.

[12] ZAGORECKI, A., RISTVEJ, J., KLUPA, K. Analytics for protecting critical infrastructure. Communications - Scientific Letters of the University of Zilina [online]. 2015, 17(1), p. 111-115. ISSN 1335-4205, eISSN 2585-7878. Available from: http://komunikacie.uniza.sk/index.php/communications/article/view/402

[13] BRIDA, P., MACHAJ, J., BENIKOVSKY, J. A modular localization system as a positioning service for road transport. Sensors [online]. 2014, 14(11), p. 20274-20296. ISSN 1424-8220. Available from: https://doi.org/10.3390/s141120274

[14] BREZONAKOVA, A., SKVAREKOVA, I., PECHO, P., DAVIES, R., BUGAJ, M., KANDERA, B. The effects of back lit aircraft instrument displays on pilots fatigue and performance. Transportation Research Procedia [online]. 2019, 40, p. 1273-1280. ISSN 2352-1465. Available from: https://doi.org/10.1016/j.trpro.2019.07.177

[15] ROSTAS, J., SKULTETY, F. Are today's pilots ready for full use of GNSS technologies? Transportation Research Procedia [online]. 2017, 28, p. 217-225. ISSN 2352-1465. Available from: https://doi.org/10.1016/j.trpro.2017.12.188 


\section{Annex - Nomenclature}

The abbreviation

ABAS

ADS-B

DME

DFMC

FAA

GNSS

GPS

GBAS

ITU

ICAO

ILS

LPV

MAPt

NAVSTAR

PBN

RNSS

$\mathrm{RF}$

SBAS

TAWS

VOR
The full name

Airborne Based Augmentation Systems

Automatic Dependent Surveillance-Broadcast

Distance Measuring Equipment

Dual Frequency Multi Constellation Services

United States' Federal Aviation Administration

Global Navigation Satellite System

Global Positioning System

Ground Based Augmentation System

International Telecommunication Union

International Civil Aviation Organization

Instrument Landing System

Localizer Performance with Vertical guidance

Missed Approach Point

Navigation Signal for Timing and Ranging

Performance Based Navigation

Radionavigation Satellite Service

Radio Freqency

Satellite Based Augmentation System

Terrain Avoidance Warning Systems

VHF Omni-Directional Range 